\title{
Prediction of Wind Velocity to Raise Vortex-Induced Vibration through a Road-Rail Bridge with Truss-Shaped Girder
}

\author{
Seungtaek Oh $\mathbb{D}^{1},{ }^{1}$ Sung-il Seo, ${ }^{2}$ Hoyeop Lee, ${ }^{1}$ and Hak-Eun Lee $\mathbb{C}^{1}$ \\ ${ }^{1}$ Department of Architectural, Civil and Environmental Engineering, Korea University, Seoul 02841, Republic of Korea \\ ${ }^{2}$ New Transportation Research Center, Korea Railroad Research Institute (KRRI), Uiwang-si, Gyeonggi-do 16105, \\ Republic of Korea \\ Correspondence should be addressed to Hak-Eun Lee; helee@korea.ac.kr
}

Received 22 February 2018; Accepted 16 July 2018; Published 27 August 2018

Academic Editor: Rafał Burdzik

Copyright (C) 2018 Seungtaek Oh et al. This is an open access article distributed under the Creative Commons Attribution License, which permits unrestricted use, distribution, and reproduction in any medium, provided the original work is properly cited.

\begin{abstract}
Vortex-induced vibration (VIV) of bridges, related to fluid-structure interaction and maintenance of bridge monitoring system, causes fatigue and serviceability problems due to aerodynamic instability at low wind velocity. Extensive studies on VIV have been performed by directly measuring the vortex shedding frequency and the wind velocity for indicating the largest girder displacement. However, previous studies have not investigated a prediction of wind velocity to raise VIV with a various natural frequency of the structure because most cases have been focused on the estimation of the wind velocity and peeling-off frequency by the mounting structure at the fixed position. In this paper, the method for predicting wind velocity to raise VIV is suggested with various natural frequencies on a road-rail bridge with truss-shaped girder. For this purpose, 12 cases of dynamic wind tunnel test with different natural frequencies are performed by the resonance phenomenon. As a result, it is reasonable to predict wind velocity to raise VIV with maximum RMS displacement due to dynamic wind tunnel tests. Furthermore, it is found that the natural frequency can be used instead of the vortex shedding frequency in order to predict the wind velocity on the dynamic wind tunnel test. Finally, curve fitting is performed to predict the wind velocity of the actual bridge. The result is shown that predicting the wind velocity at which VIV occurs can be appropriately estimated at arbitrary natural frequencies of the dynamic wind tunnel test due to the feature of Strouhal number determined by the shape of the cross section.
\end{abstract}

\section{Introduction}

Vortex-induced vibration (VIV) is usually classified as a detrimental factor that causes bridge fatigue and serviceability problems due to aerodynamic instability at low wind velocity in the operating status of a bridge [1-3]. Therefore, predicting VIV caused by wind loads is an important factor in the maintenance of the bridge. In addition, predicting the wind velocity to raise VIV plays an important role in knowing the detrimental event with a harmful vibration in advance because predicting the wind velocity to raise VIV means predicting the conditions for generating VIV.

VIV phenomenon is estimated by the Strouhal number (St) proposed by Vincenc Strouhal [4] in 1878. The Strouhal number, a dimensionless coefficient determined by the shape of the structure, is expressed by the vortex shedding frequency $\left(f_{\mathrm{s}}\right)$, the structure shape, the wind velocity $(V)$, and the shape parameter $(D)$. That is, for a given shape, the Strouhal number is determined by the current $f_{\mathrm{s}}$ and $U$, as given by

$$
\mathrm{St}=\frac{f_{\mathrm{s}} \times D}{U}
$$

In the field of Strouhal number research for VIV phenomenon, extensive and valuable experimental studies have been conducted with circular and rectangular cylinder mounted at a fixed position. Okajima [5] conducted experiments on the vortex shedding frequencies of rectangular cylinder in the range of Reynolds number on the condition mounted at a fixed position, and it was found that flow pattern changes in a certain range of Reynolds number. 
Knisely [6] determined the Strouhal number of rectangular cylinder mounted at a fixed position with various range of Reynolds number and angle of attack. Roshko [7] conducted wind tunnel test of circular cylinders, which was mounted at a fixed position at various Reynolds number, and it is suggested the formula between the Strouhal number and Reynolds number of circular cylinder divided into two areas of Reynolds number ranging from 50 to 150 and from 300 to 2000. Williamson [8] focused on two-dimensional (2-D) and three-dimensional (3-D) vortex dynamics of circular cylinder mounted at fixed position using various experimental techniques. In addition, Sakamoto and Haniu [9] conducted wind tunnel test and flow visualization using mounted spheres at a fixed position, and vortex shedding patterns of sphere are classified in five characteristic regions according to changing of Reynolds number. Apart from numerical simulations, Song et al. [10] used a simple cable-stayed bridge model with the fixed position subjected to a distributed vortex shedding force, which is related to fluid flow around an immersed structure.

Various experimental techniques have been investigated to measure the vortex shedding frequency and wind velocity. Larsen and Walther [11] calculated the Strouhal number of a simple-shaped bridge model using the discrete vortex method and compared results with the wind tunnel test. Schewe and Larsen [12] conducted a task which is accomplished in the high pressure wind tunnel situated for obtaining the Strouhal number of a cross section at typical model scale $\left(\mathrm{Re} \approx 10^{5}\right)$ and prototype condition scale $(\mathrm{Re} \approx$ $10^{7}$ ) for Reynolds number. Diana et al. [13] showed free motion test rig with configuration permits to execute VIV test changing the constraint conditions. In this work, the definition of bridge deck's Strouhal number is the measurement of the maximum displacement value with the identification of the lock-in region. Strømmen and HjorthHansen [14] performed experiments using a stiffer rig with respect to various damping level to reduce the VIV amplitude and showed the possibility that the Strouhal number could be obtained from natural frequency. Belloli et al. [15] described the VIV characteristics of multibox girders through the measurement of aerodynamic forces and surface pressure distributions. Sarwar and Ishihara and Anina et al. $[16,17]$ numerically analyzed to estimate the vortex-induced vibration of the box girder bridge section. In addition, Noto used a smoke-wire experimentation [18], and von Ellenrieder and Pothos [19] and Hain et al. [20] used a particle image velocimetry (PIV) to visualize the vortex at uniform flow. Recently, a study on the estimation of the Strouhal number through the dynamic wind tunnel test [21] was carried out, but the wind velocity was not determined by the proposed method because it used the Strouhal number obtained through the ensemble average of the spectrum.

On the related research for VIV, $\mathrm{He}$ and $\mathrm{Li}$, Tao et al., Laima et al., and Wu et al. [22-25] conducted the dynamic wind tunnel test using spring supported system, but their research was not focused on estimating the wind velocity. $\mathrm{He}$ and $\mathrm{Li}$ paid attention to the fact that the geometrical effects of the girders can have the mitigation effect of the amplitude of the vortex oscillation. Tao et al. compared circular cylinder displacement with and without vortex generators at various angles. Laima et al. investigated the influences for geometric attachments with flow separation effects. Wu et al. showed that multiple VIV regions could be present in a specific geometric wide flat box girder, and the region was called "multi-lock-in regions."

In the field of monitoring system and maintenance of the structure, the investigations for VIV on long-span bridge are very rare, and the cross section experimental results of the VIV according to the scale are used to evaluate the influence of the behavior of the prototype structure. Frandsen [1] conducted an investigation of the wind velocity and amplitude of VIV to compare scale effects of $1: 60,1: 80$, and $1: 200$ on Great Belt East bridge, and the comparison of results between scale effects shows that the larger the scale, the lower the wind velocity. Larsen et al. [26] conducted an investigation of the vortex shedding response of twin box bridge section model on scale of $1: 20$ and $1: 80$ with and without guide vanes at bottom plate of girder, and the result shows the soffit mounted guide vanes can be efficient devices for preventing VIV. Li et al. [2] used field measurement data for observed VIV phenomena. Design Manual for Roads and Bridges (DMRB) [27], for highway structures, suggested a formula for predicting the wind velocity to raise VIV by several types of a bridge shape according to effective width and depth ratio, but effective width and depth ratio of roadrail bridge with truss-shaped girder type was not suggested.

The Strouhal number has to be a constant value for the same cross-sectional shape of the bridge because the Strouhal number is determined by the shape of the structure. In addition, the vortex shedding frequency is proportional to the wind velocity by (1), which represents a constant value for the same cross-sectional shape. Since VIV is a resonance phenomenon that occurs when the vortex shedding frequency and the natural frequency of the bridge are close to each other, these values can be evaluated as similar when resonance occurs. Choi and Kwon's previous result [21] shows that the values of vortex-induced frequency and structure vibration frequency are almost similar in case of lock-in by the self-excited oscillation method. Therefore, the self-excited oscillation method is applied for predicting wind velocity to raise VIV.

In this paper, Sections 2-5 contain the following contents: In Section 2, 12 cases of dynamic wind tunnel tests are conducted on road-rail bridge with a truss-shaped girder, and the root mean square (RMS) displacement is shown. In Section 3, the Strouhal number is estimated from the dynamic wind tunnel test results, and it is confirmed that the value of the Strouhal number is constantly estimated at the arbitrary natural frequency of the same cross-sectional shape. Section 4 is divided into three parts. In Section 4.1, the similarity between the vortex shedding frequency and the natural frequency of a structure is compared, and it is shown that the wind velocity to raise VIV can be predicted reasonably even when using the natural frequency instead of the vortex shedding frequency. In Section 4.2, the estimated wind velocity and the measured wind velocity error are compared according to the estimated Strouhal number at an arbitrary natural frequency by assuming that the Strouhal 
number extracted from the test is the Strouhal number estimated from an arbitrary natural frequency. In Section 4.3, curve fitting for predicting the wind velocity to raise VIV according to the natural frequency of the structure is proposed from the dynamic wind tunnel test data of 12 cases in the case of the tested structure shape. According to the properties of the Strouhal number determined by the shape of the structure, the method of estimating the wind velocity to raise VIV at any structural frequency is reasonably measured when the bridge shape is constant. Also, it is shown that the wind velocity can be reasonably estimated with a dynamic wind tunnel test even if the natural frequency of the test structure is unknown.

\section{Dynamic Wind Tunnel Test}

2.1. Model Setup. As mentioned in introduction, estimating the Strouhal number of a complicated bridge section is possible by using the resonance phenomenon through a dynamic wind tunnel test. In order to estimate the Strouhal number of the complicated bridge section, the Yeoungjong Bridge in Korea was selected as the cross section of the wind tunnel test model. The Yeoungjong Bridge is a road-rail suspension bridge with a width of $41 \mathrm{~m}$ and a height of $12 \mathrm{~m}$. It is composed of six upper lanes, two lower lanes for the road, and two lanes for the rail. The details of the cross section and side of the bridge are shown in Figure 1.

The wind tunnel test was carried out at Korea University in Korea. A two degree of freedom test was performed with a uniform air flow condition as shown in Figure 2. Two laser displacement meters (LK-2101 and LK-081 from KEYENCE) were placed to measure the motion of the bridge due to wind load, and an air flow transducer anemometer (model 6332D from Kanomax) was placed for wind velocity measurement. NI devices were used for data acquisition (BNC-2110 board, PCI-6221 M Series from NI) and programmed using Labview 2010 software.

The scale for the wind tunnel test is $75: 1$, and the scaled dynamic parameters used in the test are shown in Table 1. The dynamic wind tunnel tests were carried out for 12 cases by changing the value of the vertical and torsional natural frequency of the bridge. The values of vertical frequency were divided into 3 different values of $1.12 \mathrm{~Hz}, 1.5 \mathrm{~Hz}$, and $1.89 \mathrm{~Hz}$, respectively. And for each vertical frequency case, the torsion to vertical frequency ratio was divided by 1.1, 1.3, 1.6, and 2.0. The natural frequency of the wind tunnel test cases is summarized in Table 2. For each case, damping ratio was set at about $0.2 \sim 0.3(\%)$.

2.2. Test Result. Figure 3 shows the test results at $1.89 \mathrm{~Hz}$, $1.12 \mathrm{~Hz}$, and $1.50 \mathrm{~Hz}$ vertical frequencies, respectively. In each figure, four RMS torsional frequency graphs are shown according to the ratio of torsional and vertical frequency. It can be confirmed that torsional VIV occurs in all cases. As shown in the graphs, the peak value of the VIV appears to be expressed at higher wind speeds as the torsional natural frequency of the structure is set higher. From the above results, it is shown that the wind velocity to raise VIV can be estimated according to the torsional frequency of the structure.

\section{Estimating Strouhal Number}

In the case that VIV occurs in a road-rail bridge with a trussshaped girder, the Strouhal number can be estimated by the wind velocity and the vortex shedding frequency when the frequency is close to the natural frequency of the structure. This is due to the fact that the vortex vibration is a resonance phenomenon. In this paper, the following method is used to estimate the Strouhal number:

(a) Measure the time series response of structures subjected to wind loads at set natural frequencies through a dynamic wind tunnel test.

(b) The measured time series response for each wind speed is converted into a frequency response by fast Fourier transform (FFT).

(c) In the frequency response area, select a frequency range with a frequency that is similar to the structure frequency set in the test.

(d) Determine the Strouhal number using the vortex shedding frequency and the wind velocity at the value of maximum amplitude of FFT.

Figure 4 shows the signal with a maximum amplitude of FFT in order to determine the Strouhal number from the wind tunnel test by the method above. Figure 4(a) shows the time history signal of the torsional displacement at vertical frequency of $1.12 \mathrm{~Hz}$, frequency ratio of 1.1 , and a wind velocity of $5.215 \mathrm{~m} / \mathrm{s}$. Figure 4 (b) shows the result of FFT of the time history signal of Figure 4(a). As shown in Figure 4(a), in time history signal, it can be seen that the torsional vibration appears constant in the section where VIV occurs. As a result of this FFT, the frequency of this amplitude is $1.229 \mathrm{~Hz}$, and the Strouhal number of this section can be calculated from this frequency, wind velocity, and representative length.

For all cases of the results of the 12 experimental cases at each frequency, the Strouhal number is obtained using maximum amplitude of FFT and wind velocity. The mean value of Strouhal number is 0.323 , and the maximum error value of that is $-3.279 \%$ as shown in Table 3. Each percent error is shown in Figure 5 by chart for visualization. From Figure 5, it can be seen that the Strouhal number has almost a similar value for all the cases since the Strouhal number is determined by the shape of the structure. From this result, it can be seen that the value of the Strouhal number can be constantly estimated using the above method.

\section{Prediction of Wind Velocity to Raise VIV}

4.1. Difference between Vortex Shedding Frequency and Natural Frequency. In Section 3, the Strouhal number is estimated when the FFT amplitude has the maximum value. In this section, the differences between the vortex shedding frequency and the natural frequency are analyzed. The vortex shedding frequency is determined in accordance with 
550.000 ( Yeongjong Bridge, Korea )

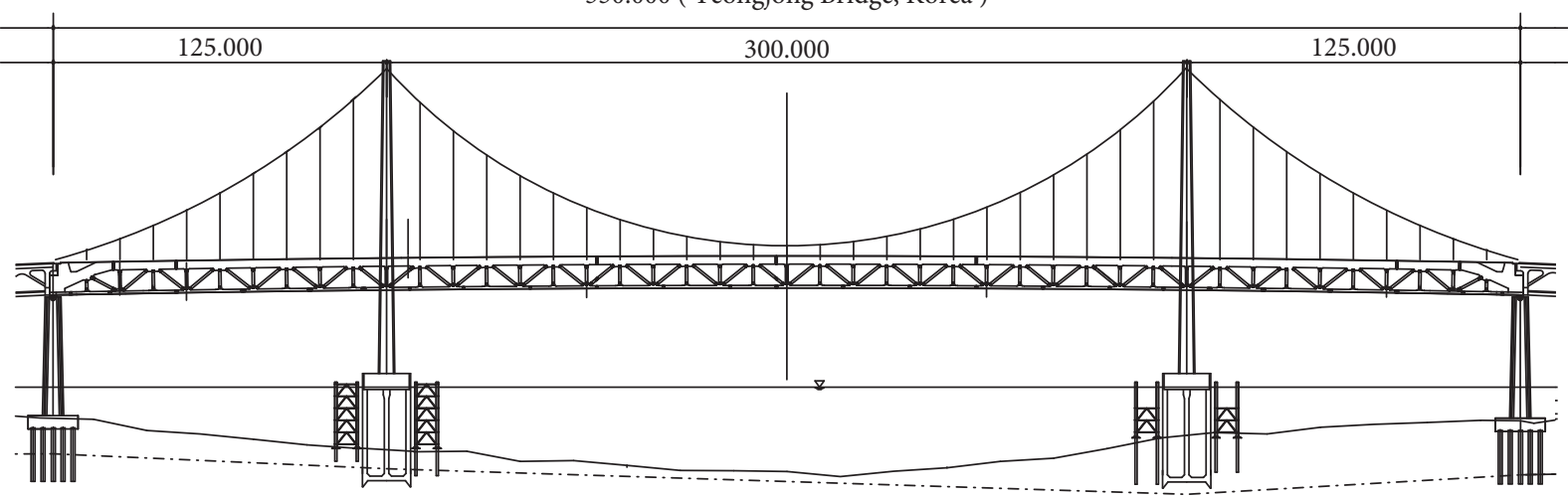

(a)

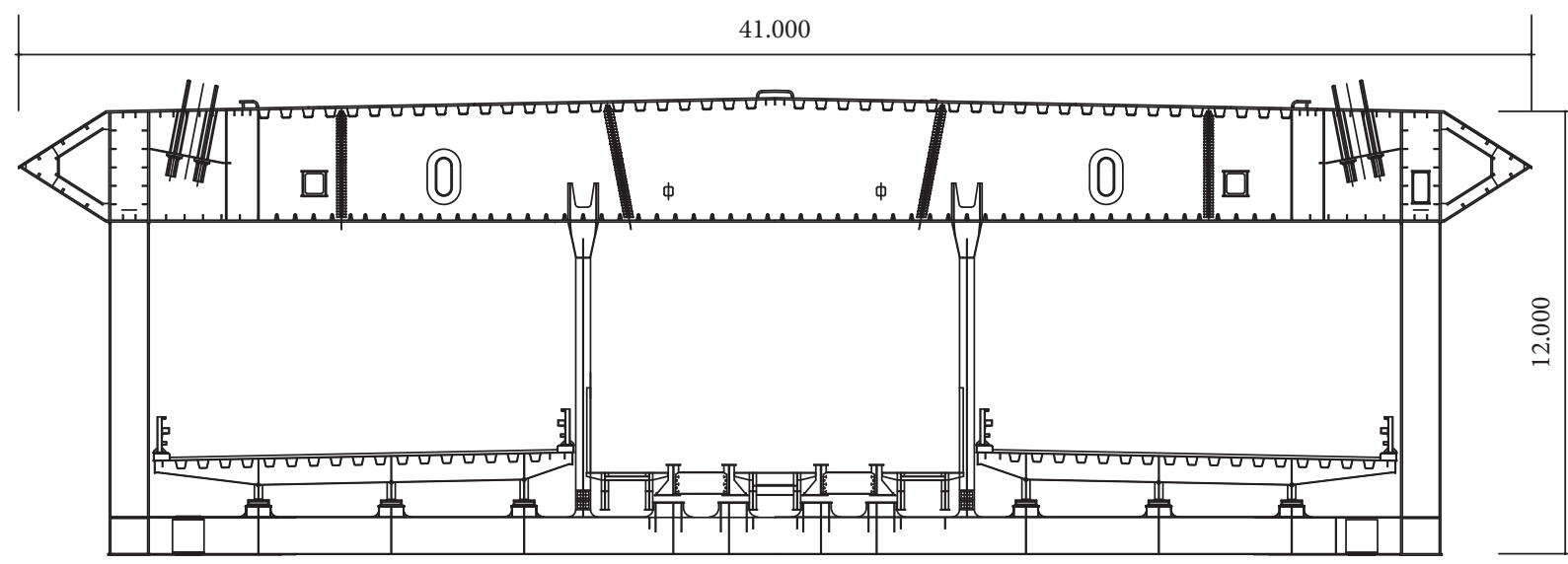

(b)

Figure 1: Yeongjong Bridge, in Korea. (a) Side of the bridge. (b) Cross section of the bridge.

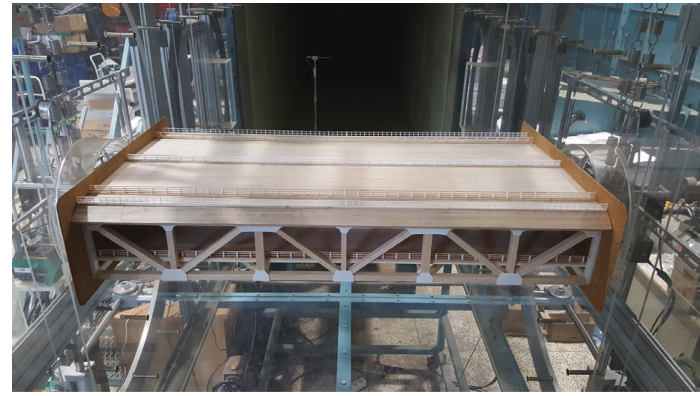

(a)

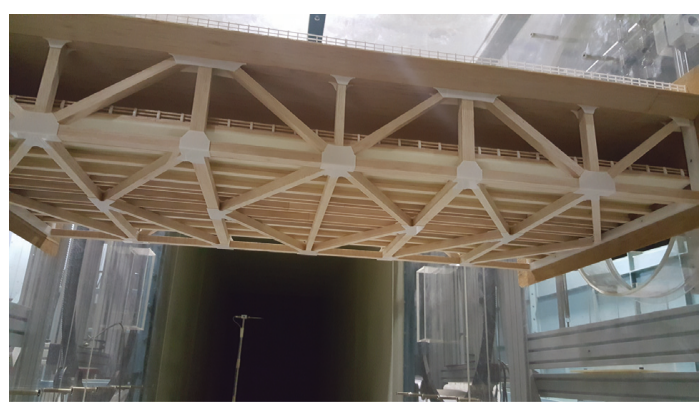

(c)

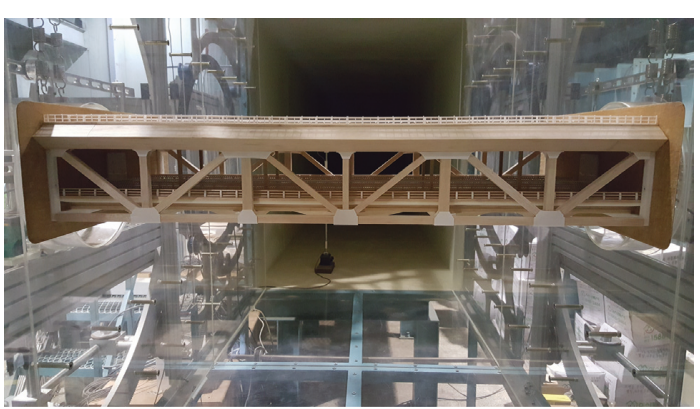

(b)

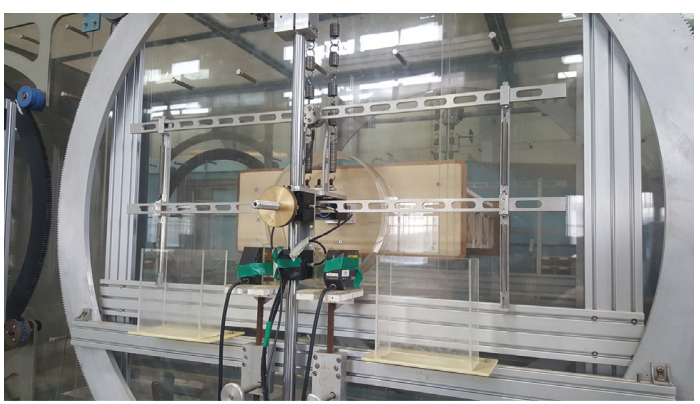

(d)

FIgUre 2: Dynamic wind tunnel test setup. (a) Front view of the bridge. (b) Side view of the bridge. (c) Under view of the bridge. (d) Outside view of the bridge. 
TABLE 1: Design parameters of wind tunnel tests.

\begin{tabular}{lcc}
\hline Parameters & Actual values & Testing values \\
\hline Width $(\mathrm{m})$ & 41 & 0.547 \\
Height $(\mathrm{m})$ & 12 & 0.160 \\
Mass per unit length $(\mathrm{kg} / \mathrm{m})$ & 45,380 & 8.068 \\
Mass moment of inertia per unit length $\left(\mathrm{kg} \cdot \mathrm{m}^{2} / \mathrm{m}\right)$ & $7,068,000$ & 0.223 \\
Flow condition & - & Uniform flow \\
\hline
\end{tabular}

TABle 2: Frequency parameters.

\begin{tabular}{lccc}
\hline Experimental cases & Vertical frequency $(\mathrm{Hz})$ & Torsional frequency $(\mathrm{Hz})$ & Frequency ratio (torsional/vertical) \\
\hline 1 & & 1.238 & 1.1 \\
2 & 1.12 & 1.463 & 1.3 \\
3 & & 1.788 & 1.6 \\
4 & & 2.244 & 2.0 \\
5 & & 1.656 & 1.1 \\
6 & 1.50 & 1.956 & 1.3 \\
7 & & 2.406 & 1.6 \\
8 & & 3.013 & 2.0 \\
9 & & 2.100 & 1.1 \\
10 & 1.89 & 2.444 & 1.3 \\
11 & & 3.006 & 1.6 \\
\end{tabular}

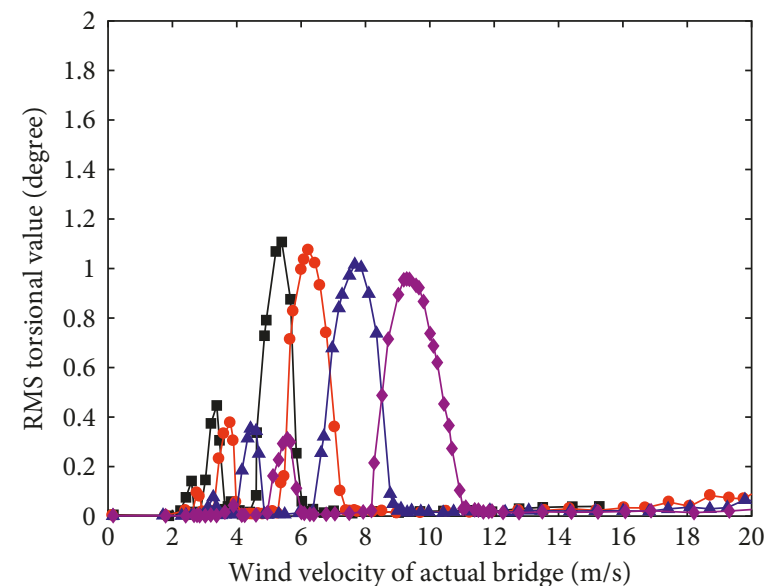

$\rightarrow$ Frequency ratio $1.1 \rightarrow$ Frequency ratio 1.6

- Frequency ratio $1.3 \longrightarrow$ Frequency ratio 2.0

(a)

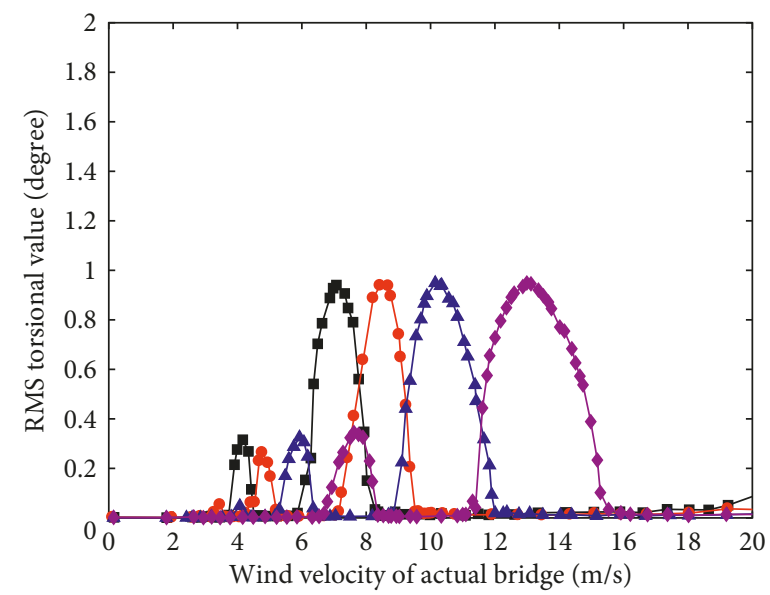

$\rightarrow$ Frequency ratio $1.1 \multimap$ Frequency ratio 1.6

(b)

FIgURE 3: Continued. 


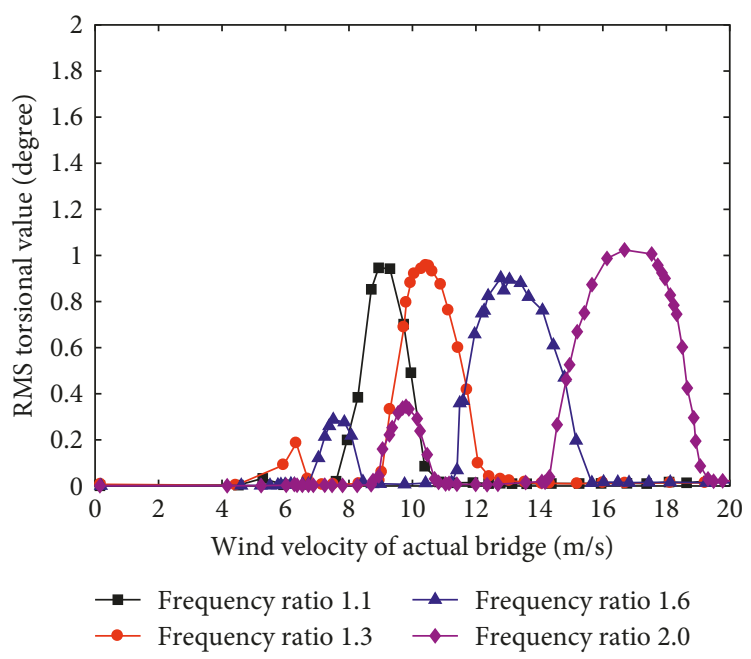

(c)

FIGURE 3: VIV of girder of bridge in different frequency parameters. (a) VIV of dynamic wind tunnel test at $1.12 \mathrm{~Hz}$ vertical frequency. (b) VIV of dynamic wind tunnel test at $1.50 \mathrm{~Hz}$ vertical frequency. (c) VIV of dynamic wind tunnel test at $1.89 \mathrm{~Hz}$ vertical frequency.

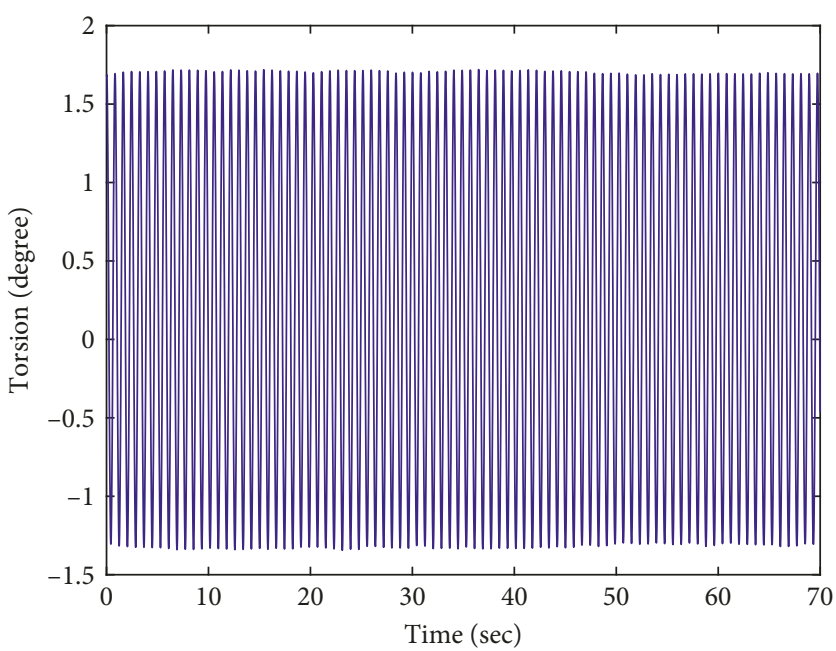

(a)

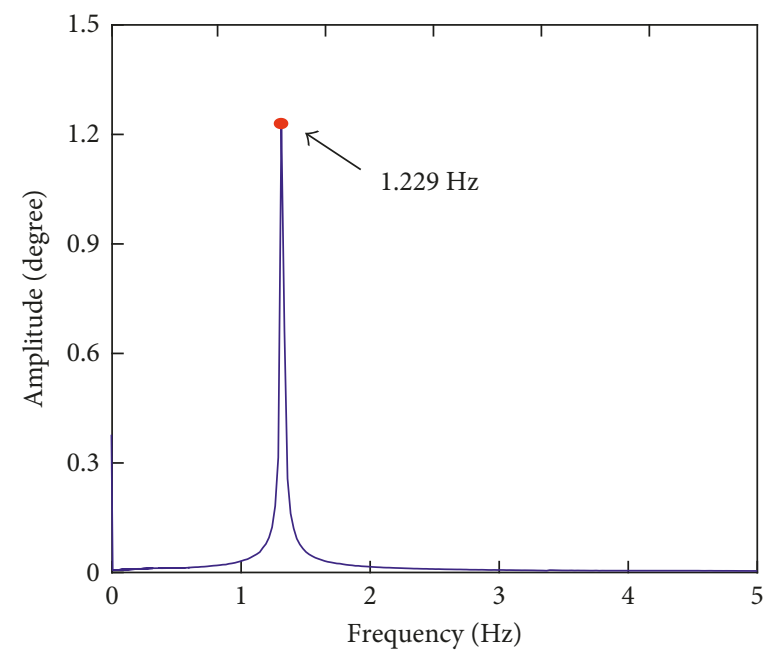

(b)

Figure 4: Signal transformation using FFT at $5.215 \mathrm{~m} / \mathrm{s}$ wind velocity. (a) Time history signal. (b) Frequency history signal.

Section 3 , and the natural frequency is the value set in the test as shown in Table 4 . The equation for the difference between the two values is as follows:

$$
\Delta_{\text {diff }}=\operatorname{abs}\left|\frac{f_{\mathrm{t}}-f_{\mathrm{s}}}{f_{\mathrm{t}}}\right| \times 100
$$

The differences between the vortex shedding frequency and the natural frequency for 12 cases are shown in Figure 6, and maximum difference value has $0.722 \%$ as shown in Table 4. According to Figure 6 and Table 4, the results show that the difference between the natural frequency and the vortex shedding frequency is almost close. These results are in agreement with Choi and Kwon's previous study [21]. Therefore, to evaluate the Strouhal number, the results show that the vortex shedding frequency can be reasonably constructed with substituting it with the natural frequency.

\subsection{Estimation of VIV Wind Velocity through Estimated} Strouhal Number at Arbitrary Natural Frequency. Through the dynamic wind tunnel test, the Strouhal number can be expressed as shown in (3a). Since the difference between the vortex shedding frequency and the natural frequency is small, the wind velocity can be estimated as shown in (3b) using natural frequency instead of vortex shedding frequency. In the first case, the Strouhal number is estimated from the natural frequency corresponding to test case 1 , and the difference between the measured wind velocity and estimated wind velocity is compared for each case by $(3 c)$. 
TABle 3: Strouhal number estimation with dynamic wind tunnel test.

\begin{tabular}{lcc}
\hline Experimental cases & Mean value of Strouhal number & $\begin{array}{c}\text { Percent } \\
\text { error }\end{array}$ \\
\hline 1 & -2.989 \\
2 & 0.323 & 0.554 \\
3 & & 0.721 \\
4 & & 1.781 \\
5 & 1.119 \\
6 & & 0.377 \\
7 & & -0.037 \\
8 & 2.777 \\
9 & & 0.549 \\
10 & -3.279 \\
11 & 1.533 \\
12 & -3.107 \\
\hline
\end{tabular}

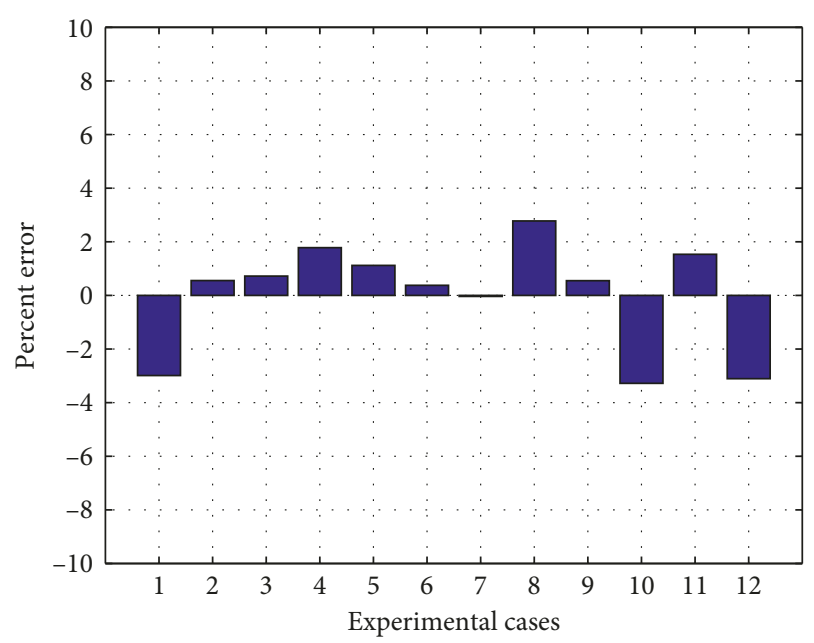

Figure 5: Percent errors of Strouhal number from the results of dynamic wind tunnel test.

$$
\begin{aligned}
S_{\mathrm{s}} & =\frac{f_{\mathrm{s}} \times D}{U_{\mathrm{s}}}, \\
U_{\text {estimated }} & =\frac{f_{\mathrm{t}} \times D}{S_{\mathrm{s}}}, \\
U_{\text {diff }} & =\operatorname{abs}\left|\frac{U_{\text {measured }}-U_{\text {estimated }}}{U_{\text {estimated }}}\right| \times 100 .
\end{aligned}
$$

Table 5 shows the predicted wind velocity to raise VIV from case 2 to case 12 using the Strouhal number obtained from the test case 1 . The Strouhal number $\left(S_{s}\right)$ is 0.3132 , torsional natural frequency $\left(f_{\mathrm{t}}\right)$ is the value set for each case, and the width $(D)$ is $12 / 75$. The measured wind velocity to raise VIV for each case obtained from the wind tunnel test shows that the maximum error is $5.986 \%$.

Applying the above method for all 12 cases using (3c), 12 estimated wind velocities can be obtained for all cases. The differences between the estimated wind velocity and measured wind velocity is shown in Figure 7 . The difference is a maximum of $6.304 \%$, and this result shows that the wind velocity to raise VIV can be appropriately predicted through the Strouhal number even with dynamic wind tunnel tests at an arbitrary frequency.

4.3. Curve Fitting of Wind Velocity to Raise VIV by Natural Frequency. Since the wind velocity to raise VIV can be predicted at an arbitrary frequency as shown in Section 4.2, the curve fitting related to the prediction of the wind velocity according to the natural frequency changes of the structure is proposed by the dynamic wind tunnel test with 12 cases. Although more accurate wind velocity results are estimated if the Reynolds number effect is considered, according to Frandsen [1], as the section model scale approaches the scale of the actual structure, the wind velocity of VIV tends to increase. Therefore, it can be expected that the wind velocity of the actual structure will be larger than the estimating value of wind velocity of scaled-section model by present scale. Figure 8 shows the wind velocity according to the natural frequency for each test case. The curve fitting is shown through the trend of each case. It is approximated as a firstorder polynomial function because the wind velocity is proportional to the natural frequency according to the definition of the estimated wind velocity in (3b). Considering scale effect, the curve fitting function is predicted as $f(x)=36.706 x+0.106$ as shown in Figure $8(a)$, and the sum of squares due to error (SSE) is 0.760 as shown in Figure 8(b). According to effects of Reynolds number, it can be expected that the wind velocity of actual scale can be estimated over than $45 \mathrm{~m} / \mathrm{s}$ because the first torsional frequency of the actual bridge is $1.23 \mathrm{~Hz}$. Also, it is shown that the wind velocity can be predicted according to the change of the natural frequency in maintenance and monitoring of the bridge.

\section{Conclusion}

In this paper, experimental investigations of prediction of wind velocity to raise VIV that generates the maximum RMS displacement amplitude are conducted on a road-rail bridge with truss-shaped girder. For this purpose, dynamic wind tunnel tests for 12 cases of various frequencies are conducted. In the condition that VIV occurs, it is found that the wind velocity to raise VIV increases as the natural frequency of the structure increases due to the feature of Strouhal number determined by the shape of the cross section. In addition, the Strouhal number can also be reasonably estimated by the dynamic wind tunnel test at an arbitrary frequency, since results show that the maximum error of the Strouhal number among the 12 cases represents $3.279 \%$.

Furthermore, it is found that the natural frequency can be used instead of the vortex shedding frequency in order to predict the wind velocity on the dynamic wind tunnel test, since results show that the difference between the vortex shedding frequency and natural frequency represents only a maximum value of 0.722 , and the maximum difference represents $6.304 \%$ when the wind velocity to raise VIV is predicted by using the mean value of Strouhal number. 
TABLE 4: Differences between vortex shedding frequency and natural frequency.

\begin{tabular}{lccc}
\hline Test cases & Vortex shedding frequency, $f_{\mathrm{s}}(\mathrm{Hz})$ & Natural frequency, $f_{\mathrm{t}}(\mathrm{Hz})$ & Difference $\left(\Delta_{\text {diff }}\right)$ \\
\hline 1 & 2.100 & 2.100 & \\
2 & 2.443 & 2.444 & \\
3 & 3.000 & 3.006 & \\
4 & 3.771 & 3.788 & $\max \left|\Delta_{\text {diff }}\right|=0.722 \%, \Delta_{\text {diff }} \simeq 0$ \\
5 & 1.229 & 1.238 & \\
6 & 1.457 & 1.463 & \\
7 & 1.786 & 1.788 & \\
8 & 2.243 & 2.244 & 1.656 \\
9 & 1.657 & 1.956 & \\
10 & 1.957 & 2.406 & \\
11 & 2.400 & 3.013 & \\
\hline
\end{tabular}

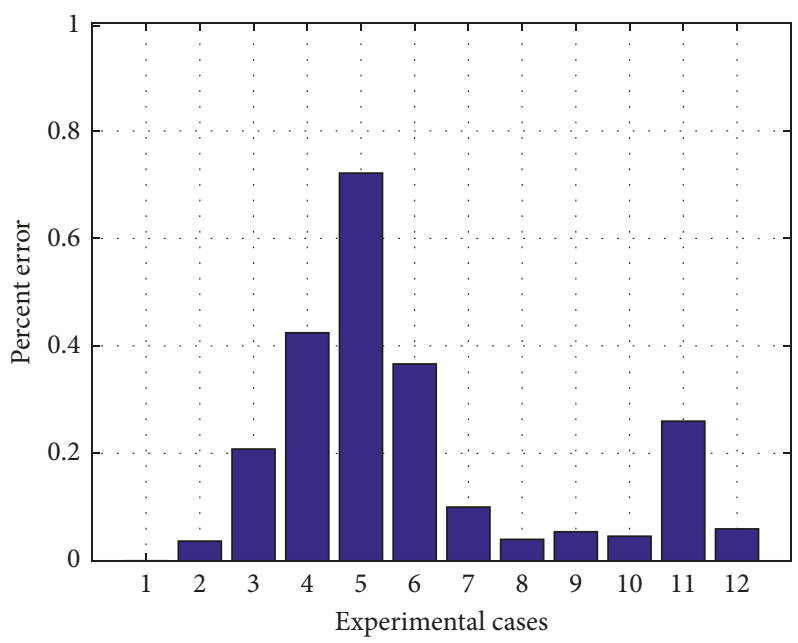

FIGURE 6: Difference between vortex shedding frequency and natural frequency.

TABle 5: Differences between measured wind velocity and estimated wind velocity.

\begin{tabular}{lccc}
\hline Experimental cases & Measured wind velocity $U_{\text {measured }}(\mathrm{m} / \mathrm{s})$ & Estimated wind velocity $U_{\text {estimated }}(\mathrm{m} / \mathrm{s})$ & Difference $\left(U_{\text {diff }}\right)(\%)$ \\
\hline 1 & 1.0728 & 1.0728 & 0.0000 \\
2 & 1.2040 & 1.2484 & 3.6896 \\
3 & 1.4761 & 1.5358 & 4.0398 \\
4 & 1.8364 & 1.9349 & 5.3635 \\
5 & 0.6021 & 0.6322 & 4.9916 \\
6 & 0.7194 & 0.7471 & 3.8491 \\
7 & 0.8853 & 0.9132 & 3.1458 \\
8 & 1.0815 & 1.1462 & 5.9856 \\
9 & 0.8168 & 0.8461 & 3.5910 \\
10 & 1.0028 & 0.9994 & 0.3451 \\
11 & 1.1715 & 1.2293 & 4.9336 \\
12 & 1.5418 & 1.5390 & 0.1807 \\
\hline
\end{tabular}

Finally, curve fitting is performed to predict the wind velocity of the actual bridge by using scale factor. Since the road-rail bridge with truss-shaped girder is a very special shape, this result can be used as a reference value for estimating wind velocity to raise VIV that generates the maximum RMS displacement amplitude.

This result can be used as a reasonable way to predict the wind velocity to raise VIV for changes in natural frequency. 


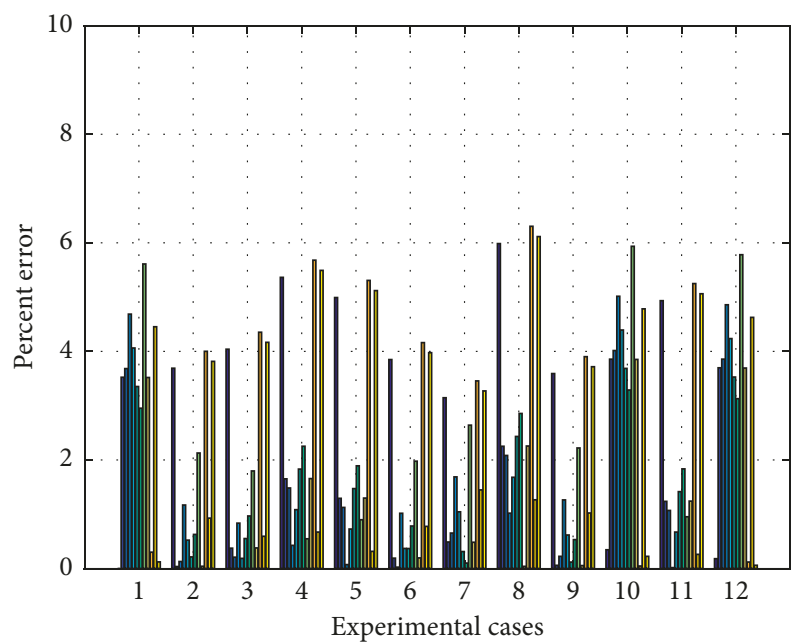

FIGURE 7: VIV occurrence velocity prediction error for all 12 cases.
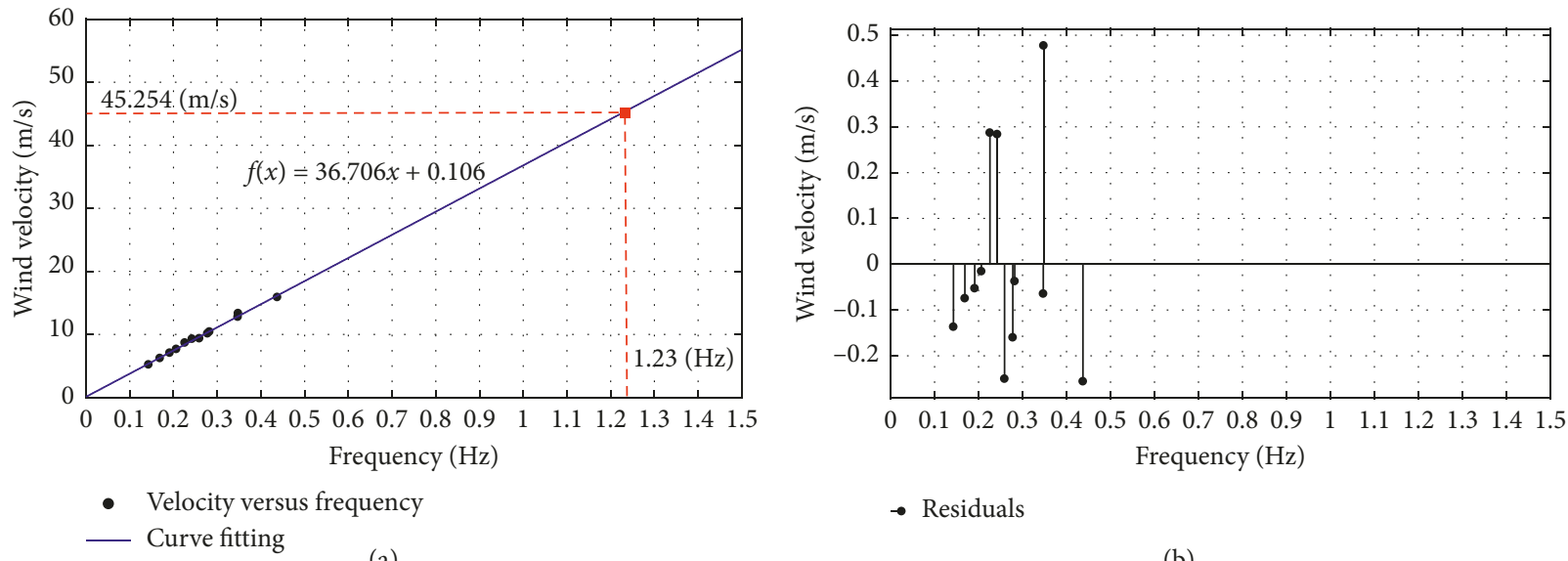

(a)

(b)

FIGURE 8: Wind velocity to raise VIV according to structural frequency and curve fitting. (a) Curve fitting for predicting wind velocity to raise VIV to the change of the natural frequency. (b) Residuals from the curve fitting.

And it is likely to contribute to the field of maintenance and monitoring system of the structure.

\section{Data Availability}

The data used to support the findings of this study are available from the corresponding author upon request.

\section{Conflicts of Interest}

The authors declare that there are no conflicts of interests regarding the publication of this paper.

\section{Acknowledgments}

This research was supported by a grant from R\&D Program of the Korea Railroad Research Institute, Republic of Korea, and partially supported by a Korea University grant.

\section{References}

[1] J. Frandsen, "Simultaneous pressures and accelerations measured full-scale on the Great Belt East suspension bridge," Journal of Wind Engineering and Industrial Aerodynamics, vol. 89, no. 1, pp. 95-129, 2001.

[2] H. Li, S. Laima, J. Ou et al., "Investigation of vortex-induced vibration of a suspension bridge with two separated steel box girders based on field measurements," Engineering Structures, vol. 33, no. 6, pp. 1894-1907, 2011.

[3] L. Zhou and Y. Ge, "Wind tunnel test for vortex-induced vibration of vehicle-bridge system section model," Journal of the Brazilian Society of Mechanical Sciences and Engineering, vol. 30, no. 2, pp. 110-117, 2008.

[4] V. Strouhal, "Über eine besondere art der tonerregung," Annalen der Physik, vol. 241, no. 10, pp. 216-251, 1878.

[5] A. Okajima, "Strouhal numbers of rectangular cylinders," Journal of Fluid Mechanics, vol. 123, pp. 379-398, 1982. 
[6] C. W. Knisely, "Strouhal numbers of rectangular cylinders at incidence: a review and new data," Journal of Fluids and Structures, vol. 4, no. 4, pp. 371-393, 1990.

[7] A. Roshko, "On the development of turbulent wakes from vortex streets," NACA Technical Report 1191, 1954.

[8] C. H. Williamson, "Vortex dynamics in the cylinder wake," Annual Review of Fluid Mechanics, vol. 28, no. 1, pp. 477-539, 1996.

[9] H. Sakamoto and H. Haniu, "A study on vortex shedding from spheres in a uniform flow," Journal of Fluids Engineering, vol. 112, no. 4, pp. 386-392, 1990.

[10] M. T. Song, D. Q. Cao, and W. D. Zhu, "Vortex-induced vibration of a cable-stayed bridge," Shock and Vibration, vol. 2016, Article ID 1928086, 14 pages, 2016.

[11] A. Larsen and J. H. Walther, "Aeroelastic analysis of bridge girder sections based on discrete vortex simulations," Journal of Wind Engineering and Industrial Aerodynamics, vol. 67, pp. 253-265, 1997.

[12] G. Schewe and A. Larsen, "Reynolds number effects in the flow around a bluff bridge deck cross section," Journal of Wind Engineering and Industrial Aerodynamics, vol. 74, pp. 829-838, 1998.

[13] G. Diana, F. Resta, A. Zasso, M. Belloli, and D. Rocchi, "Forced motion and free motion aeroelastic tests on a new concept dynamometric section model of the Messina suspension bridge," Journal of Wind Engineering and Industrial Aerodynamics, vol. 92, no. 6, pp. 441-462, 2004.

[14] E. Strømmen and H. Hjorth-Hansen, "Static and dynamic section model tests of the proposed Hardanger fjord suspension bridge," in Proceeding of Bridges into the 21st Century, pp. 251-258, Hong Kong, 1995.

[15] M. Belloli, F. Fossati, S. Giappino, and S. Muggiasca, "Vortex induced vibrations of a bridge deck: dynamic response and surface pressure distribution," Journal of Wind Engineering and Industrial Aerodynamics, vol. 133, pp. 160-168, 2014.

[16] M. W. Sarwar and T. Ishihara, "Numerical study on suppression of vortex-induced vibrations of box girder bridge section by aerodynamic countermeasures," Journal of Wind Engineering and Industrial Aerodynamics, vol. 98, no. 12, pp. 701-711, 2010.

[17] S. Anina, H. Rüdiger, and B. Stanko, "Numerical simulations and experimental validations of force coefficients and flutter derivatives of a bridge deck," Journal of Wind Engineering and Industrial Aerodynamics, vol. 144, pp. 172-182, 2015.

[18] K. Noto, K. Matsuzaki, and T. Nakajima, "Visualization of the Karman vortex street generated at low Reynolds numbers due to natural convection," Transactions of the Japan Society of Mechanical Engineers Series B, vol. 64, no. 617, pp. 219-225, 1998.

[19] K. D. von Ellenrieder and S. Pothos, "PIV measurements of the asymmetric wake of a two dimensional heaving hydrofoil," Experiments in Fluids, vol. 44, no. 5, pp. 733-745, 2008.

[20] R. Hain, C. J. Kähler, and D. Michaelis, "Tomographic and time resolved PIV measurements on a finite cylinder mounted on a flat plate," Experiments in Fluids, vol. 45, no. 4, pp. 715-724, 2008.

[21] C. K. Choi and D. K. Kwon, "Determination of the Strouhal number based on the aerodynamic behavior of rectangular cylinders," Wind and Structures, vol. 3, no. 3, pp. 209-220, 2000.

[22] H. X. He and J. W. Li, "Study on the effect and mechanism of aerodynamic measures for the vortex-induced vibration of separate pairs of box girders in cable-stayed bridges," Shock and Vibration, vol. 2015, Article ID 792957, 11 pages, 2015.
[23] S.-b. Tao, A.-p. Tang, D.-b. Xin, K.-t. Liu, and H.-f. Zhang, "Vortex-induced vibration suppression of a circular cylinder with vortex generators," Shock and Vibration, vol. 2016, Article ID 5298687, 10 pages, 2016.

[24] S. Laima, H. Li, W. Chen, and J. Ou, "Effects of attachments on aerodynamic characteristics and vortex-induced vibration of twin-box girder," Journal of Fluids and Structures, vol. 77, pp. 115-133, 2018.

[25] B. Wu, L. Zhang, Y. Yang, L. Liu, and H. Li, "Investigation and control of VIVs with multi-lock-in regions on wide flat box girders," Journal of Control Science and Engineering, vol. 2017, Article ID 7208241, 17 pages, 2017.

[26] A. Larsen, M. Savage, A. Lafrenière, M. C. Hui, and S. V. Larsen, "Investigation of vortex response of a twin box bridge section at high and low Reynolds numbers," Journal of Wind Engineering and Industrial Aerodynamics, vol. 96, no. 67, pp. 934-944, 2008.

[27] SGD DMRB, "Highway structures: approval procedures and general design," in Part 3: BD 49/01 Design Rules for Aerodynamic Effects on Bridges, Vol. 1, SGD DMRB, London, UK, 2001. 


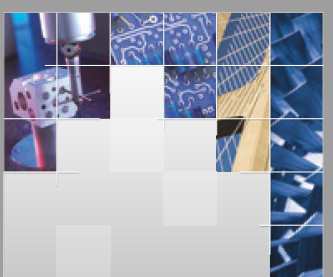

\section{Enfincering}
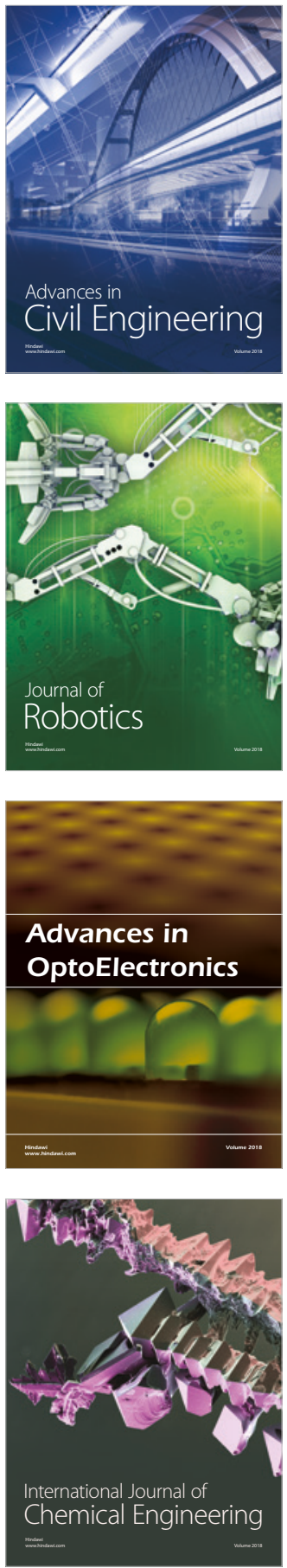

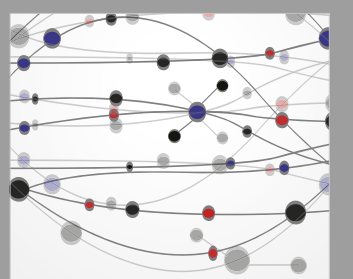

\section{Rotating \\ Machinery}

The Scientific World Journal

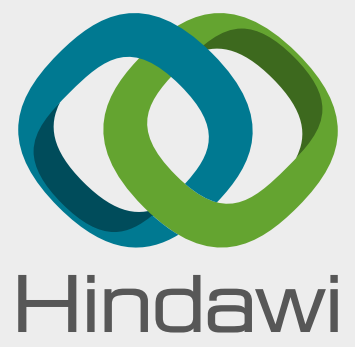

Submit your manuscripts at

www.hindawi.com
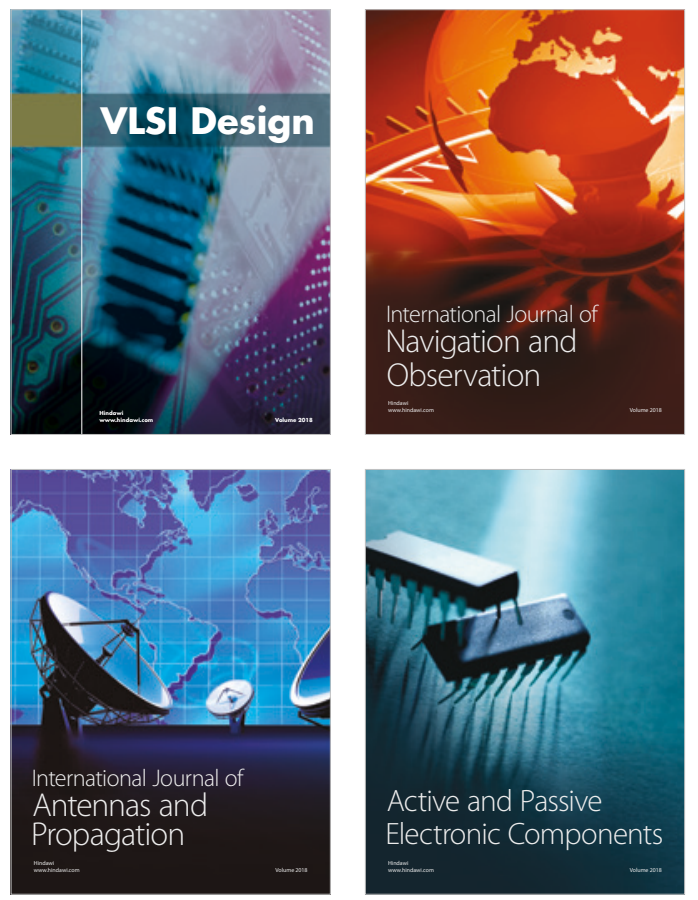
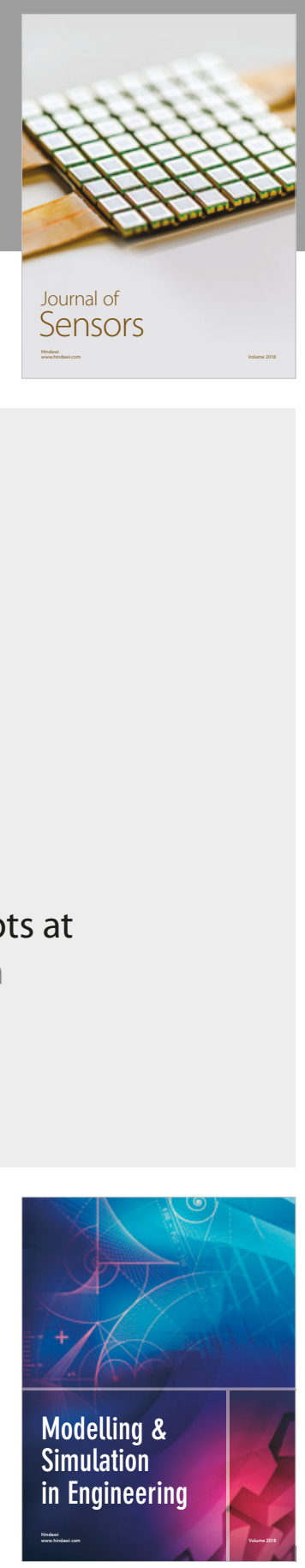

\section{Advances \\ Multimedia}
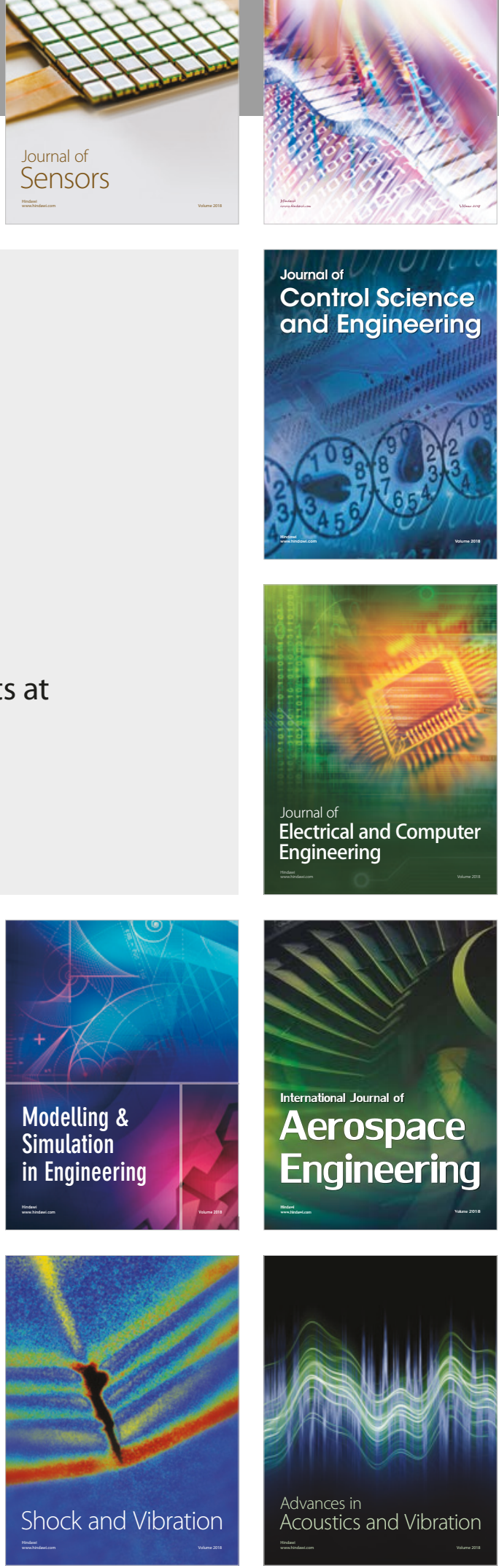